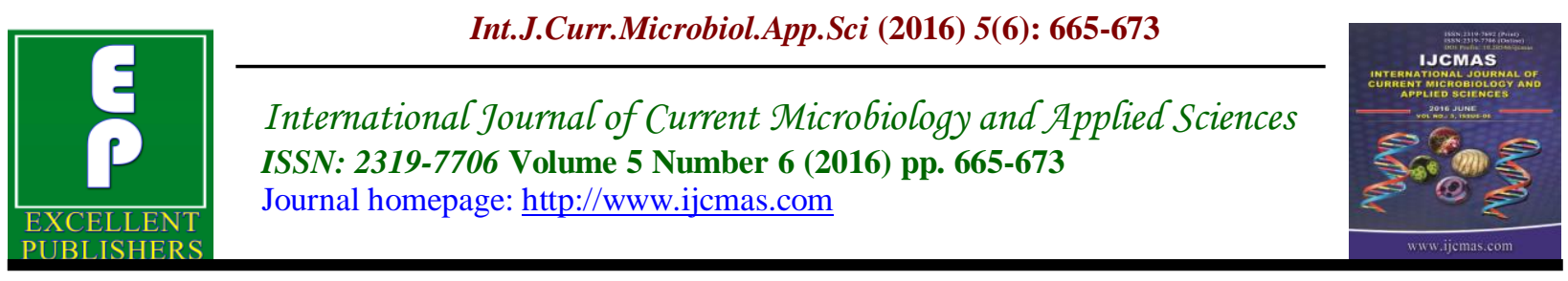

Original Research Article

http://dx.doi.org/10.20546/ijcmas.2016.506.072

\title{
Optimization of PHB (poly-hydroxybutyrate) Synthesis by Serratia sp. Isolated from Soil
}

\author{
Sinha Kritika ${ }^{1}$, RathorePragya $^{2}$, PhanseNandini ${ }^{3}$ and SentiyaPriti ${ }^{1}$ \\ ${ }^{1}$ Pacific Academy of Higher education and research, Udaipur, India \\ ${ }^{2}$ Sanghvi Institute of Management and Science, Indore, India \\ ${ }^{3}$ P.M.B. Gujarati Science College, Indore, India \\ *Corresponding author
}

\section{Keywords}

Polyhydroxy-

butyrate,

bioplastics, biodegradable, polyhydroxyalkanoates, biocompatible, polymers.

\begin{tabular}{l}
\hline Article Info \\
\hline Accepted: \\
23 May 2016 \\
Available Online: \\
10 June 2016
\end{tabular}

\section{A B S T R A C T}

Accumulation of plastics and other similar compounds have created havoc in the environment. To overcome this situation, an alternative to such petrochemical xenobiotic compounds is the need of the hour. Polyhydroxybutyrate (PHB), belongs to a family of microbial energy storage compounds collectively known as polyhydroxyalkanoates. These are biodegradable and biocompatible polymers that are accumulated as reserve granules by certain microorganisms intracellularly under carbon rich and nitrogen deficient conditions. PHB, as a bioplastic, has proved itself a promising alternative against the non-degradable petroplastics. PHB of biological origin can be completely degraded into carbon dioxide and water. In the present study, different PHB producing microorganisms were isolated from soil using E2 medium and its rapid screening for PHB producers was performed by plate assay method using Sudan Black B dye. Out of 76 different isolates obtained, 34 isolates were found to be positive PHB producers. They were then subjected to spectrophotometric quantitation method described by Jhon and Ralph. The highest producer was identified by biochemical characterization as of Serratia sp. and was optimized with certain parameters for its PHB production. After optimization, PHB production was quantified by two methods, \% PHB production against dry cell mass (DCM) and HPLC. Both the methods concluded the production $\sim 37 \%$.

\section{Introduction}

The adverse effects of the widespread use of the petrochemical plastics have directed the search for eco-friendly and biodegradable plastics. These plastics are biologically degradable under appropriate conditions and can be produced from cheap sources such as waste products, by many microorganisms (Jain, Costa, Tiwari, 2010). The low cost, stability, durability, good mechanical and thermal properties of plastic makes it the best choice for widespread applications (Amara, 2008). Bacterial Polyhydroxyalkanoates (PHA) share the characteristics with conventional plastics such as polypropylene (Madison and Huisman, 1999) and can be used for the production of eco-friendly bioplastics or rather green plastics. Poly (3- 
hydroxybutyrate) (PHB) is the best characterized PHA.

Polyhydroxybutyrate (PHB) from bacterial source (Alcaligenes eutrophus), was first isolated and characterized in 1925 (Lemoigne, 1926). PHB has widespread occurrence in both Gram-positive and negative bacteria (Anderson and Dawes, 1990) ${ }^{2}$. Many references show that number of microorganisms like Alcaligene eutrophus, Azotobacter beijierinckia, Pseudomonas oleovorans, Rhizobium sp., etc., produce PHBs as reserve food material under nutrient-limiting conditions with excess carbon. These are formed as inclusion bodies when nutrient medium have limited oxygen, nitrogen, phosphorous, sulphur or magnesium and an excess of carbon source (Kim et al., 1994; Lee, 1996). PHB can grow in a wide variety of natural environments and is the reserve polymer (intracellular granules) found in many types of bacteria found in nature, e.g. in soil, sea water, sewage sludge or compost (Prasanna et al., 2011). They can be used in different applications such as packaging film and containers, surgical pins and sutures and bone replacements. PHB degrade naturally and completely to $\mathrm{CO}_{2}$ and $\mathrm{H}_{2} \mathrm{O}$ under natural environment by different microorganisms. PHB exists in the cytoplasmic fluid in the form of crystalline granule about $0.5 \mathrm{~m}$ in diameter. $\mathrm{P}$ hydroxybutyrate is connected by ester linkage and form PHB. This can be extracted from the cells as native granule or by solvent extraction (Senthil and Prabakaran, 2006).

\section{Materials and Methods}

\section{Isolation and Screening}

The organisms were isolated from different industrial effluents on E 2 medium by preparing serial dilutions of the effluent and inoculated on E 2 medium (Phanse et al., 2011). The colonies obtained were screened for their ability to produce PHB. Rapid screening of colonies form PHB production, on E2 agar medium, was performed by Plate assay method using Sudan Black B dye. Accumulation of PHB granules in isolates was observed by Sudan black staining method.

\section{Quantitation}

The positive isolates were subjected to quantitation of PHB accumulated. For the quantification of the PHB produced by the organisms, the PHB was first extracted from the cells and then quantified by spectrometry by the method described by Jhon and Ralph (1961). The culture was centrifuged 10,000 rpm for 10 minutes and pellet was suspended in $4 \%$ sodium hypochlorite. Again centrifugation was performed and then treated with chloroform and sulfuric acid. This was then subjected to spectrophotometric analysis and the optical density (OD) was measured at $235 \mathrm{~nm}$.

\section{Characterization}

The highest producer was identified and characterized on the basis of their cultural, morphological and biochemical characters.

\section{Optimization of PHB production}

The best producer after characterization was optimized for its production of PHBs. The factors studied were different carbon sources, different nitrogen sources, different concentrations of best nitrogen source, different $\mathrm{pH}$, different temperatures, different $\mathrm{C}: \mathrm{N}$ ratio.

\section{Determination of Dry Cell Mass (DCM)}

Isolate was incubated in E2 medium with the optimized results for PHB production 
and after 48 hours of incubation at $30^{\circ} \mathrm{C}, 10$ $\mathrm{mL}$ of culture was taken for centrifugation. The cell pellet was washed with phosphate buffer and centrifuged. Pellet was washed with sterile deionised water, dried at $100^{\circ} \mathrm{C}$ for $24 \mathrm{hrs}$ and incubated at $60^{\circ} \mathrm{C}$ for $1 \mathrm{hr}$ with $4 \%(\mathrm{v} / \mathrm{v})$ sodium hypochlorite and centrifuged at $6000 \mathrm{rpm}$ for $15 \mathrm{~min}$ and $\mathrm{PHB}$ was extracted using acetone alcohol method.

\section{Extraction of PHB}

After the above step of centrifugation, the pellet was treated with acetone for washing and methanol for extraction. After washing, the pellet was dissolved in $5 \mathrm{~mL}$ of boiling chloroform and was evaporated. After evaporation, the powder was collected for further analysis.

\section{Extraction by Acetone-alcohol}

Cell mass (g/L) after 48 hours of growth was collected by centrifugation and lysed by sodium hypochlorite at $37^{\circ} \mathrm{C}$ for $1 \mathrm{hr}$. Contents were centrifuged again and the lysed cell mass was washed with distilled water and acetone: alcohol (1: 1). Precipitation was achieved in boiling chloroform $(10 \mathrm{~mL})$ and the precipitate was allowed to evaporate at room temperature to obtain PHB in powder form.

\section{Percent production of PHB was calculated by using the formula}

$\%$ of PHB $=$ Total weight of PHB / Total weight of pellet $\mathrm{x} 100$

\section{Quantitation by HPLC}

The PHB produced in the cells was again extracted and converted into crotonic acid. This crotonic acid obtained was cooled to room temperature and diluted to $50 \mathrm{X}$. This was then subjected to HPLC ion exchange organic acid column. The solvent used was $0.014 \mathrm{~N} \mathrm{H}_{2} \mathrm{SO}_{4}$ and the flow rate was 0.7 $\mathrm{ml} / \mathrm{min}$. the elution peak was monitored at $210 \mathrm{~nm}$.

\section{Results and Discussion}

\section{Screening of PHB Producing Isolates}

The organisms were isolated on E2 medium and different morphological colonies were marked for their purification. The colonies were purified on E2 medium by sector plate method. The isolates were screened for PHB production, on E2 agar medium, by Plate assay method using Sudan Black B dye (Fig.1). Accumulation of PHB granules in isolates was observed by Sudan black staining method. Isolate KJN III showed maximum accumulation of PHB by colony screening method, based on the intensity of staining.

\section{Quantitation}

The positive isolates were subjected to quantitation method explained by Jhon and Ralph (1961). Out of all the positive producers, isolate KJN III was found to be the maximum producer.

\section{Characterization}

The colonial, microscopic and biochemical characters of KJN III identified the organism as one of the Serratia sp. (Table1)

\section{Optimization of PHB production}

PHB production was checked spectrophotometrically at different $\mathrm{pH}$, temperature, carbon sources, nitrogen sources, and incubation period (fig 2). The results for the optimization were statistically analyzed by ANNOVA using the SPSS 16 and the $\mathrm{p}$ value obtained was 0.02 . 


\section{PHB Production against Dry Cell Mass}

\begin{tabular}{|l|l|}
\hline \multicolumn{2}{|l|}{ Dry cell mass } \\
\hline Initial weight $(\mathrm{W})$ & 24.28 \\
\hline Final weight $(\mathrm{W} 1)$ & 26.12 \\
\hline $\mathrm{W} 2=(\mathrm{W} 1-\mathrm{W})$ & 1.84 \\
\hline PHB content & 24.28 \\
\hline Initial weight $(\mathrm{P})$ & 24.97 \\
\hline Final weight $(\mathrm{P} 1)$ & 0.69 \\
\hline $\mathrm{P} 2=(\mathrm{P} 1-\mathrm{P})$ & $37.50 \%$ \\
\hline$\% \mathrm{PHB}=\mathrm{P} 2 / \mathrm{W} 2 * 100$ &
\end{tabular}

\section{PHB estimation by HPLC}

PHB was converted into crotonic acid and analyzed by HPLC. Four standards of known concentration viz. $20 \mathrm{mg}, 40 \mathrm{mg}, 60$ $\mathrm{mg}$, and $80 \mathrm{mg}$ (fig 3,4,5,6) were first quantified to obtain its retention time. Then the sample was quantified in triplicates (fig $7,8,9)$ and whose average value was taken to calculate the RSD value.

PHB producing colonies exhibited black color with Sudan Black B dye which being lipidophilic in nature binds to the aliphatic PHB granules in the cells imparting them black colour on solid media. These colonies were subjected to quantitation to find out the best producer among the positive isolates. The best producer was identified and characterized as Serrati $s p$. by different morphological, microscopic and biochemical characters.

Table.1 Biochemical, cultural and morphological characteristics of isolate KJN III

\begin{tabular}{|c|c|c|}
\hline S.No. & Parameters & KJN III \\
\hline 1 & Colonial Characters & $\begin{array}{l}\text { Small, Round, Even, Slightly } \\
\text { raised, Opaque, Smooth, } \\
\text { Light Orange colonies }\end{array}$ \\
\hline 2 & Pigmentation & Orange Pigmentation \\
\hline 3 & Microscopic characters & Rod shaped \\
\hline 4 & Gram's Staining & Gram Negative \\
\hline 5 & Glucose fermentation & Positive \\
\hline 6 & Lactose Fermentation & Negative \\
\hline 7 & Sucrose Fermentation & Positive \\
\hline 8 & Mac Conkey agar & $\begin{array}{c}\text { Positive growth as lactose non } \\
\text { fermenter }\end{array}$ \\
\hline 9 & Starch Hydrolysis & Negative \\
\hline 10 & Lipid Hydrolysis & Positive \\
\hline 11 & Casein Hydrolysis & Positive \\
\hline 12 & Gelatin Hydrolysis & Positive \\
\hline 13 & Indole Production & Negative \\
\hline 14 & Methyl Red test & Negative \\
\hline 15 & Voges Proskeur & Positive \\
\hline 16 & Citrate Utilization & Positive \\
\hline 17 & Nitrate Reduction & Positive \\
\hline 18 & Motility & Positive \\
\hline 19 & Catalase Activity & Positive \\
\hline 20 & H2S Production & Negative \\
\hline 21 & Gas Production from Glucose & Positive \\
\hline 22 & Urease Activity & Negative \\
\hline 23 & Oxidase Activity & Negative \\
\hline 24 & Spores & Positive \\
\hline
\end{tabular}


Fig.1 1Plate assay method using Sudan Black B dye for screening isolates for PHB production

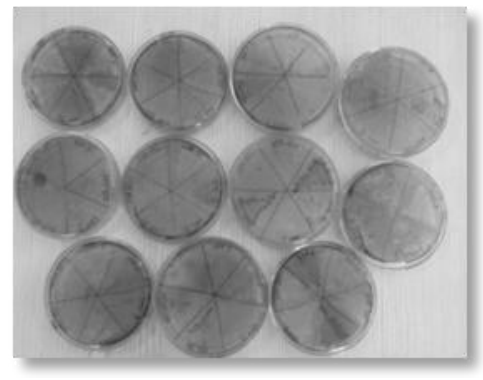

Fig.2 Optimization of PHB production
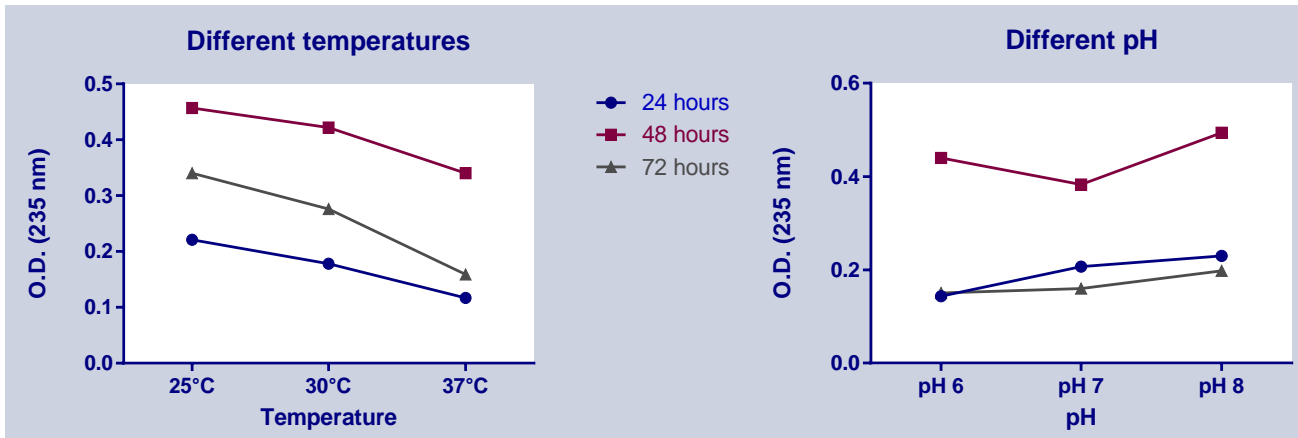

$\rightarrow 24$ hours

$\rightarrow 48$ hours

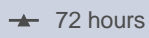

Different carbon sources

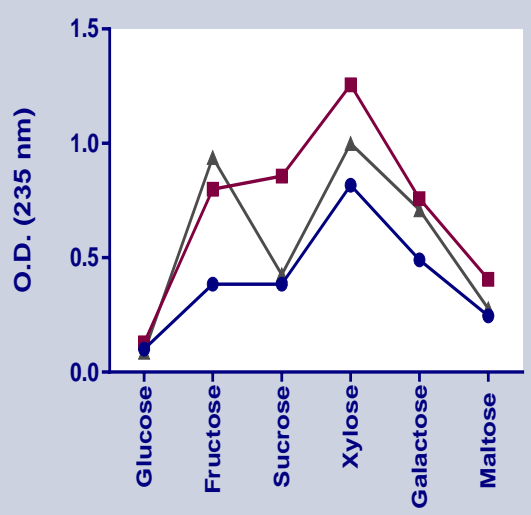

Different nitrogen sources

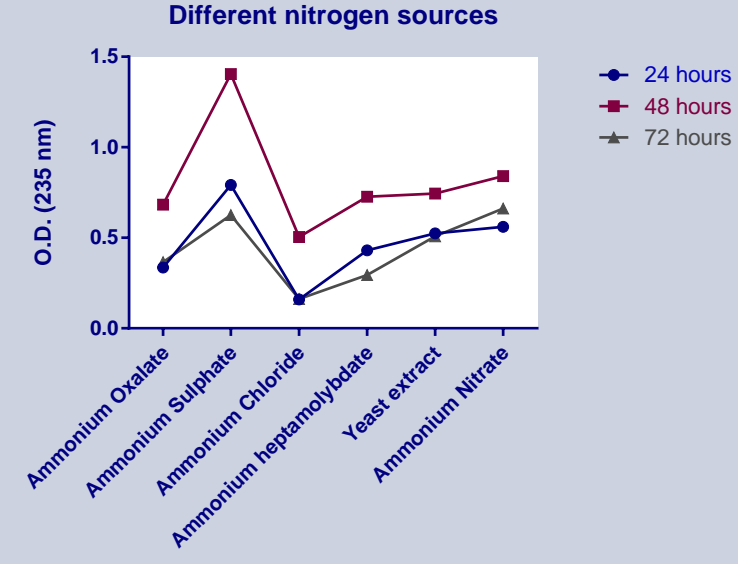

Different concentration of best nitrogen source (AS)

Int.J.Curr.Microbiol.App.Sci (2016) 5(6): 665-673

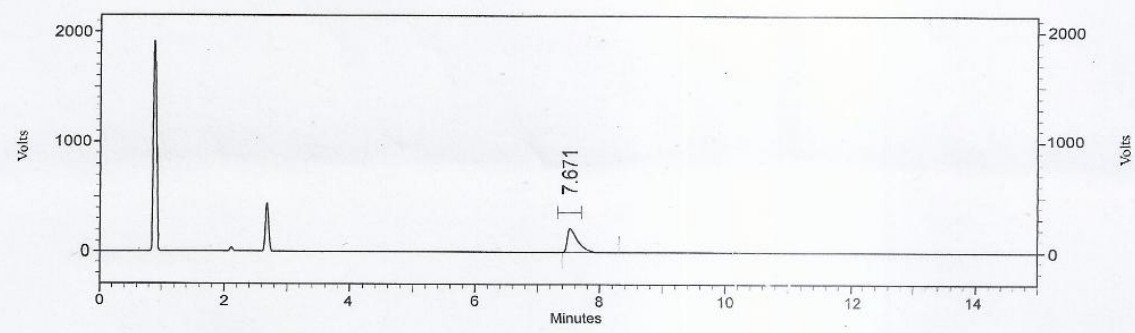

Fig.3 standard $20 \mathrm{mg}$

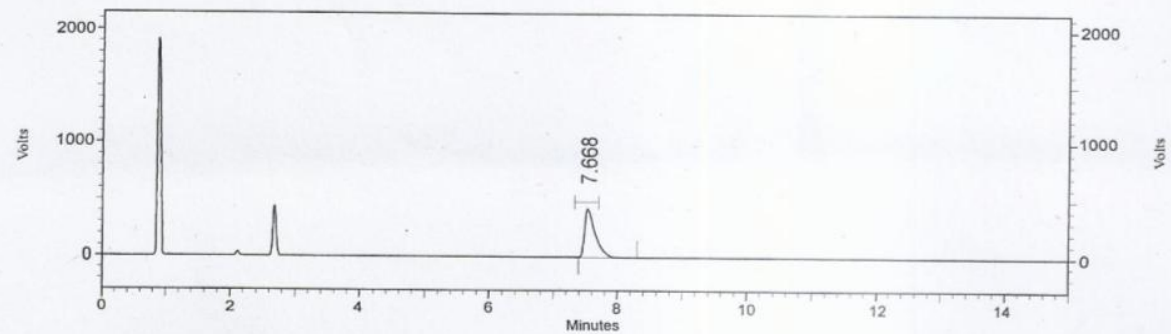

Fig.4 standard $40 \mathrm{mg}$

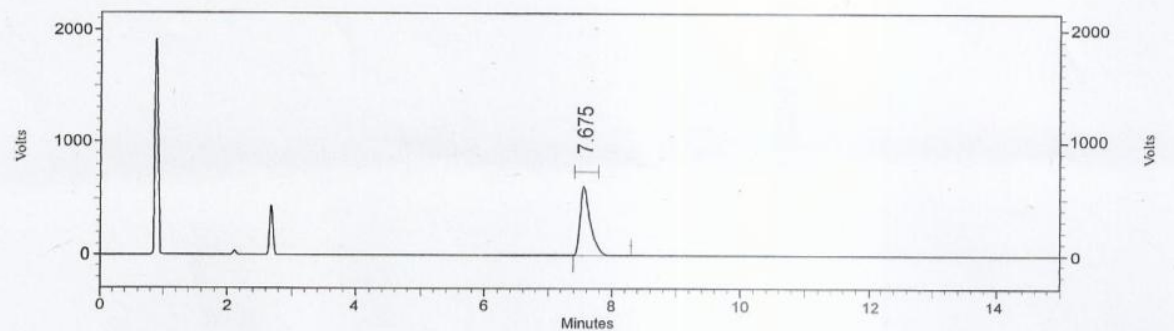

Fig.5 standard $60 \mathrm{mg}$

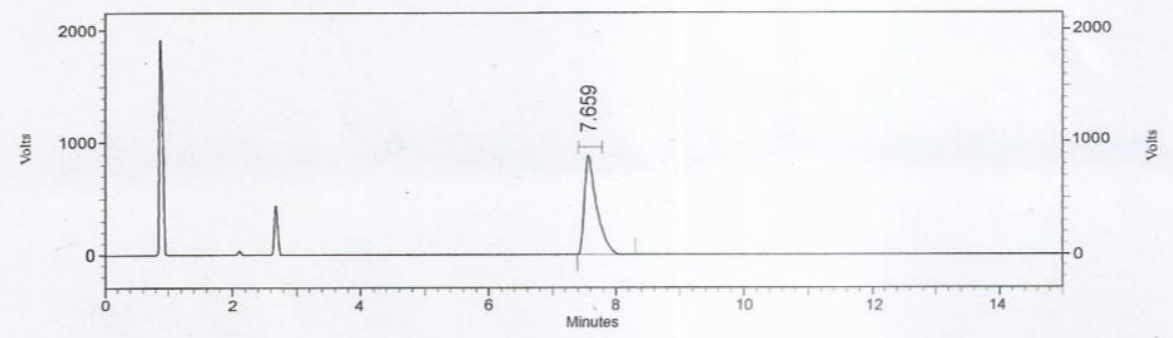

Fig.6 standard $80 \mathrm{mg}$

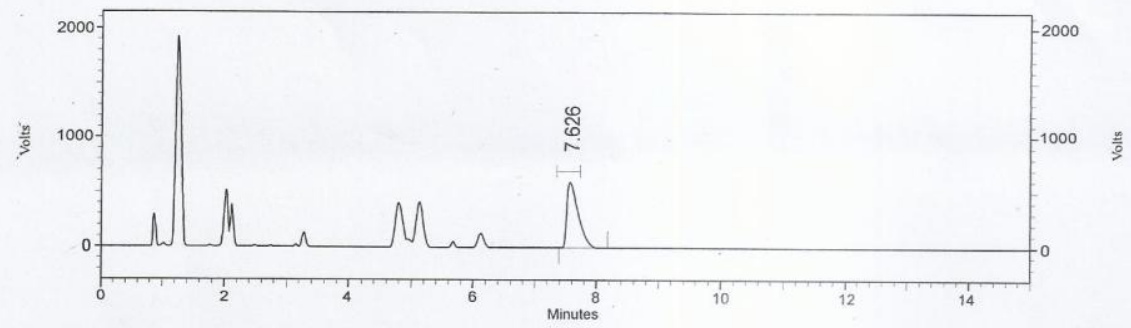

Fig.7 sample run 1 


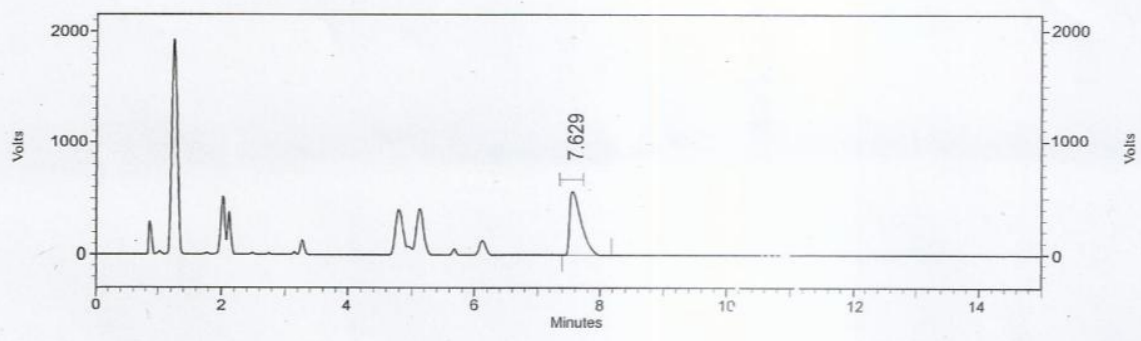

Fig.8 sample run 2

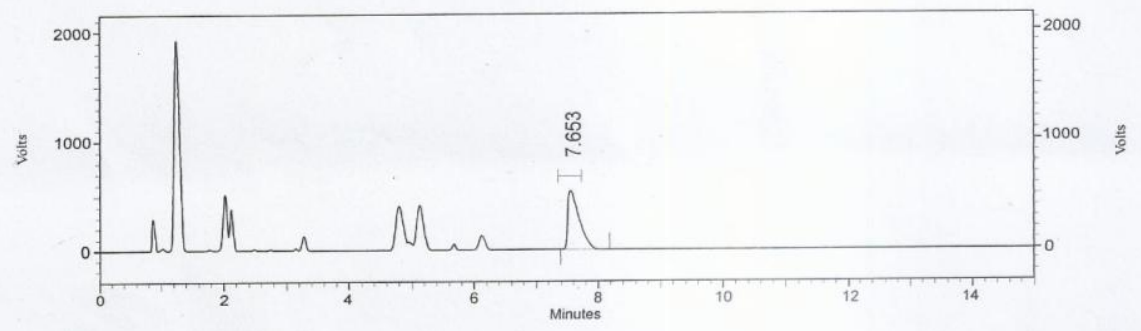

Fig.9 sample run 3

$\begin{array}{ccccc}\text { S.No. } & \text { Std Conc. } & \text { Area } & & \text { Sample } \\ 1 & 20 \mathrm{mg} / \mathrm{ml} & 159027439 & 1 & \text { Area } \\ 2 & 40 \mathrm{mg} / \mathrm{ml} & 309985878 & 2 & 471256982 \\ 3 & 60 \mathrm{mg} / \mathrm{ml} & 470025986 & 3 & 457775895 \\ 4 & 80 \mathrm{mg} / \mathrm{ml} & 639258758 & \text { AVG. } & 464011858 \\ & & & \text { STDEV } & 6796964.77\end{array}$

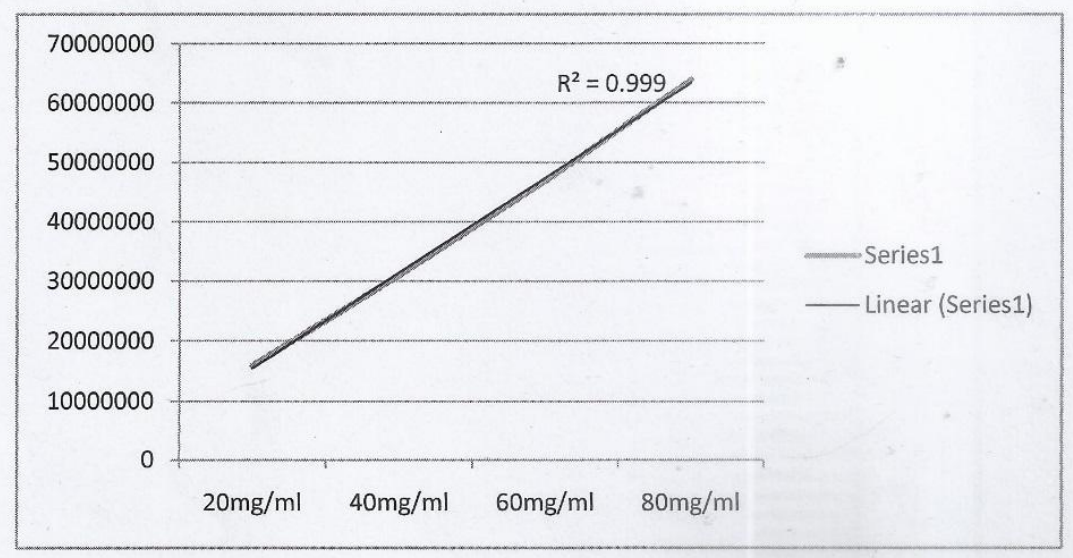

Fig.10 graph of RSD value

\begin{tabular}{|l|l|}
\hline Weight of sample taken & $1.0258 \mathrm{~g}$ dissolved in $10 \mathrm{ml}$ \\
\hline Weight of PHB taken for standard preparation & $5.0125 \mathrm{~g}$ dissolved in $50 \mathrm{ml}$ \\
\hline Potancy of PHB & $99.5 \mathrm{w} / \mathrm{w}$ \\
\hline$\%$ PHB in sample & $38.086 \% \mathrm{w} / \mathrm{w}$ \\
\hline
\end{tabular}


When xylose was used as carbon source, and ammonium sulphate as nitrogen source, the optimum $\mathrm{pH}$ observed was 7 and optimum temperature observed was $25^{\circ} \mathrm{C}$ with an incubation period of 48 hours for the organism to produce high amount of PHB. 48 hours of incubation explains the accumulation of PHB in the late exponential phase of the growth. Under the above mentioned conditions, the strain could produce $37.50 \%$ PHB of its dry cell mass which can be considered as a good amount being produced by one of the Serratia sp. The other method used for the quantitation was HPLC which involved the injections for the standards as well as the sample that was feasible to calculate the PHB potancy along with its $\%$ production. Both the methods of quantitation gave similar \% $\mathrm{PHB}$ production after optimization.

In conclusion, study on various PHB producing microorganisms was carried out in the present investigation from different industrial effluent and was found that many species are PHB accumulators and they produce $\mathrm{PHB}$ in various amounts. The isolated bacteria were quantified for their PHB accumulation and one highest producer out of all was determined as Serratia sp. by different morphological, cultural and biochemical characteristics.

This is a considerable amount produced after the maximum producing species, Alcaligenes eutrophus. Because of its rapid growth and development, it can be used in development of transgenic strains and better producers in Molecular Biology studies. It can also be used in large scale industrial fermentation process to produce PHB for its various applications like, for disposable items, such as [packaging] and catering items, Non-disposable applications include mobile phone casings, carpet fibers, and car interiors, fuel line and plastic pipe applications, Medical implants made of
PLA, which dissolve in the body, save patients a second operation, compostable mulch films for agriculture and many more.

\section{Acknowledgement}

I would like to thank Sanghvi Institute of Management and Science for providing me lab to carry on my wet lab research and central analytical lab, Rau for providing me ambience for HPLC.

\section{References}

Amara, A.A. 2008. Polyhydroxyalkanoates: from basic research and molecular biology to application, IUM Engineering J., (1): 37-73.

Anderson, A.J., Dawes, E.A. 1990. Occurrence, metabolism, metabolic role and industrial use of bacteria polyhydroxyalkanoates, Microbiol., (54): 450-472.

Dahi, M.K., Schmiedel, D., Hillen, W. 1995. Glucose and glucose -6-phosophate interaction with xylose repressor proteins from Bacillus spp. May contribute to the regulation of xylose utilization, J. Bacteriol, (177): 54675472.

Huisman, G.W., Leeuwde, O., Eggink, G., Witholt, B. 1989. Synthesis of poly-3hydroxyalkanoates is a common feature of fluorescent Pseudomonas, Appl. Environ. Microbiol., (55): 19491954.

Jain, R., Costa, S., Tiwari, A. 2010. Polyhydroxyalkanoates: A way to sustainable development of bioplastics, Chron. Joung. Sci., (1): 10-15.

Jhon, Ralph. 1961. Assay of poly- $\beta$ hydroxybutyric acid, J. Bacteriol., (1): 33-36.

Lageveen, R.G., Huisman, G.W., Preusting, H., Ketelaar, P., Eggink, G., Witholt, 
B. 1988. Formation of polyesters by Pseudomonas oleovorans: effect of substrate on formation and composition ofpoly-(R)-3hydroxyalkanoates and poly-(R)-3hydroxyalkenoates, Appl. Environ. Microbiol., (54): 2924-2932.

Lee, S.Y. 1996. a. Bacterial polyhydroxyalkanoates, Biotechnol. Bioeng, 49: 114.

Lee, S.Y. 1996. b. Plastic bacteria. Progress and prospects for polyhydroxyalkanoates production in bacteria, Tibtech, (14): 431-438.

Lemoigne, M. 1926. Products of dehydration and polymerization of $\beta$ hydroxybutyric acid, Bull. Soc. Chem. Biol., (8): 770-782.

Madison, L.L., Huisman, G.W. 1999. Metabolic engineering of poly (3hydroxyalkanoates): from DNA to plastic, Microbiol. Mol. Biol. Rev., (1): 21-53.

Phanse, N. et al. 2011. Screening of PHA (poly hydroxyalkanoate) producing bacteria from diverse sources, Int. J. Biosci., (6): 27-32.

Prasanna, et al. 2011. Production of Poly (3hydroxybutyrates) by Bacillus sp. isolated form Soil, J. Pharma Res. Rev., 15-18.

Rathore, P. 2014. Review on Bioprospects of PHB, Int. J. Emerging Trends in Sci. Technol., 529-532.

Reddy, C., Ghai, R., Kalia, V. 2003. Review paper Polyhydroxyalkanoates: an overview, Bioresource Technol., (87): 137-146.

Senthil, Prabakaran. 2006. Production of PHB (bioplastics) using bio-effluent as substrate by Alcaligeneseutrophus, Indian J. Biotechnol., (5): 76-79.

\section{How to cite this article:}

Sinha Kritika, RathorePragya, PhanseNandini and SentiyaPriti. 2016. Optimization of PHB (poly-hydroxybutyrate) Synthesis by Serratia sp. Isolated from Soil. Int.J.Curr.Microbiol.App.Sci. 5(6): 665-673. doi: http://dx.doi.org/10.20546/ijcmas.2016.506.072 